\title{
Results of Scleral Buckling Surgery in Rhegmatogenous Retinal Detachment
}

\author{
Ahmet Alperen Koc, Gokhan Demir, Okkes Baz, Ali Demircan, Dilek Yasa, Sibel Ahmet, Zeynep Alkin, \\ Muhittin Taskapili
}

University of Health Sciences, Beyoglu Eye Training and Research Hospital, Istanbul, Turkey

\begin{abstract}
Objectives: The aim of this study was to present the anatomical and functional results of scleral buckling (SB) surgery performed in cases of rhegmatogenous retinal detachment (RRD).

Methods: Retrospectively, IOI eyes of IOI patients who underwent SB surgery were included in the study. Anatomica success or failure was assessed by slit-lamp microscopy fundus examination. Best corrected visual acuity (BCVA) measurements were performed on all patients at baseline and at control visits. Preliminary and posterior segment examinations were performed with slit-lamp biomicroscopy, and intraocular pressure measurements were performed with Goldman applanation tonometry. The general characteristics of the patients and etiological factors were also examined.

Results: The mean age of the patients was $33 \pm 16$ years. The most common risk factors were idiopathic causes and myopia, each found in $34.7 \%$ of eyes, and trauma in $18.8 \%$. The mean length of disease history was $20.2 \pm 20$ days. There was no correlation between length of disease history and anatomical and functional success. In all, $94 \%$ of the eyes were phakic, $5 \%$ were pseudophakic and I\% was aphakic. Macular involvement was present in $37(36.6 \%)$ of eyes. While there was a positive correlation between macular involvement and functional success, there was no significant difference in terms of anatomical success. At the final control, anatomical success was achieved in 67 eyes $(66.7 \%)$ and functional success in 66 eyes (65\%). Pars plana vitrectomy surgery was performed as a second operation in $33.3 \%$ of the patients. Before the SB operation, the mean BCVA was I.2 \pm 0.9 logMAR (logarithm of the minimum angle of resolution); afterwards, it increased to $0.6 \pm 0.5 \log M A R(p<0.00 I)$.

Conclusion: When SB surgery is performed with the appropriate indications in the treatment of RRD, it is an easy method to apply, has a high success rate, a low complication rate, and provides the option for a secondary surgery if it fails. Keywords: Rhegmatogenous retinal detachment, scleral buckling surgery.
\end{abstract}

\section{Introduction}

Retinal detachment, which is defined as the separation of the sensory retina from the pigment epithelium, is a condition requiring urgent surgical treatment to restore adhesion. The incidence is approximately I/I 0.000 in a year (I). Scleral buckling (SB) surgery for retinal detachment was designed and performed by Schepens in 1950 (2). In the 1980s, with the advancement of pars plana vitrectomy (PPV), a popular approach to retinal detachment surgery was introduced. Al- though SB surgery is not as widely used today as it used to be, is a preferred method and still remains valid as an irreplaceable technique in some cases.

Our aim in this study was to present the anatomical and functional outcomes of SB surgery in one clinic and the factors affecting these outcomes.

\section{Methods}

A total of $10 \mathrm{I}$ eyes of $\mathrm{IOI}$ patients who underwent SB surgery between 2010 and 2015 in the clinic with the diagno-

Address for correspondence: Ahmet Alperen Koc, MD. Beyoglu Goz Egitim ve Arastirma Hastanesi, Bereketzade Cami Sokak,

Phone: +90 5326456689 E-mail: dr.alperen.koc@gmail.com

Submitted Date: May 24, 2017 Accepted Date: September 24, 2017 Available Online Date: November 29, 2017

${ }^{\circledR}$ Copyright 2017 by Beyoglu Eye Training and Research Hospital - Available online at www.beyoglueye.com 
sis of retinal detachment were retrospectively reviewed. Patients were informed about their condition, the operation, the success rate of the treatment to be performed, and possible complications before they provided consent. All patients were treated with $360^{\circ}$ circumferential buckling, segmental buckling, or a combination of both, depending on the characteristics of the retinal detachment and the choice of the surgeon. Patients with at least 6 months of follow-up were included in the study.

Patients with any previous RRD surgery, glaucoma surgery, patients for whom vitrectomy or lens surgery was added during surgery, patients with proliferative vitreoretinopathy (PVR) grade D, patients with an intraocular foreign body, and patients with intravitreous hemorrhage that prevented visualization during surgery were excluded from the study. A complete ophthalmological examination was performed at all control visits before and after the surgery. Measurement of best corrected visual acuity (BCVA) was performed using a Snellen chart, a biomicroscopic anterior segment examination and intraocular pressure (IOP) measurement were performed with Goldman applanation tonometry, in addition to a dilated fundus examination. Age, gender, the presence of additional systemic disease, preoperative lens status, the length of time between onset of disease and admission, location of retinal tearing and detachment, presence of macular involvement, and PVR grade were recorded. PVR staging was conducted according to the classification made in 1983 by the Retina Society Terminology Committee (3). In addition, the surgical technique applied, complications experienced during and after surgery, anatomical and functional success rate, recurrence date, and recurrence surgery were examined. While anatomical success was defined as a reattached retina at the last postoperative visit, functional success was accepted as an increase in BCVA $\geq I$ line or from finger counting up to 0.05 decimals or from hand movement to finger counting.

\section{Surgical Technique}

At the onset of surgery, the ocular surface was washed with $5 \%$ povidone iodine. The conjunctiva and the capsule of Tenon were opened $360^{\circ}$ and dissected. Traction sutures were placed beneath the insertions of the exposed rectus muscle with 4/0 silk. A silicone sponge (silicone sponge 505/506/507; Mira, Inc., Uxbridge, MA, USA) was used in the local buckling, and a silicone band (silicone band 240; Mira, Inc., Uxbridge, MA, USA) and sleeve (silicone tire; 276/277, Mira, Inc., Uxbridge, MA, USA) were used in the circumferential buckling. The buckling materials were sutured to the sclera with $5 / 0$ polyester fiber sutures (Mersilene; Ethicon, Inc., Somerville, $\mathrm{NJ}$, USA). When necessary, a scleral incision was made from the side of the horizontal rectus muscle in accordance with the location of the detachment and subretinal fluid drainage was performed. The conjunctiva was closed with $8 / 0$ Vicryl sutures (Ethicon, Inc., Somerville, NJ, USA). Air, I4\% perfluoropropane, or $20 \%$ sulfur hexafluoride gas was used in eyes requiring internal tamponade.

\section{Statistical Analysis}

IBM SPSS Statistics for Windows, Version 22.0 (IBM Corp., Armonk, NY, USA) was used for the statistical analysis. BCVA levels were converted to logMAR (logarithm of the minimum angle of resolution). The finger counting and hand movement levels were recorded as 2.0 and $3.0 \log M A R$ respectively. The Kolmogorov-Smirnov test, Shapiro-Wilk test and variability coefficients were used to assess the fitness of normal distribution for the analysis of quantitative data. Parametric methods were used in the analysis of variables with normal distribution, and nonparametric methods were used in the analysis of variables without normal distribution. A paired-samples t-test or Wilcoxon test was used to compare 2 dependent groups.

\section{Results}

In all, IOI eyes of I0I patients, a group comprising 59 males and 39 females, with a mean age of $33 \pm 16$ years, were assessed. The patients were followed for a mean of $21.4 \pm 16.3$ months (range: 6-96 months). Table I is a summary of the demographic characteristics of the patients.

The most common risk factors for retinal detachment were idiopathic causes and myopia. The risk factors for retinal detachment determined are provided in Table 2.

The mean duration of disease history was $20.2 \pm 20$ days (range: I- 100 days). Of the total, 95 eyes (94\%) were phakic, $5(5 \%)$ were pseudophakic, and I (I\%) was aphakic. In addition, $37(36.6 \%)$ eyes had macular involvement. There was a significant negative correlation between macular involvement

Table I. The demographic characteristics of the patients

\begin{tabular}{lc} 
& $\mathbf{n}=\mathbf{l} \mathbf{l}$ \\
\hline Age (years) & $33 \pm 16$ \\
Gender & 59 \\
$\quad$ Male & 42 \\
$\quad$ Female & $37(36.6 \%)$ \\
Macular involvement & \\
PVR grade & 96 \\
A & 4 \\
B & 1 \\
C & $0.23 \pm 0.28$ \\
Preoperative BCVA &
\end{tabular}

BCVA: Best corrected visual acuity; PVR: proliferative vitreoretinopathy. 
Table 2. Risk factors for retinal detachment

\begin{tabular}{lcc} 
& $\mathbf{n = 1 0 1}$ & $\%$ \\
\hline Idiopathic cause & 35 & 34.7 \\
Myopia & 35 & 34.7 \\
Trauma & 19 & 18.8 \\
Lattice degeneration & 8 & 7.9 \\
Pseudophakia & 3 & 2.9 \\
Aphakia & I & I \\
\hline
\end{tabular}

and functional success $(p=0.02 ; r=-0.22)$. Retinal detachment involved I quadrant in 57 eyes (56.4\%), 2 or 3 quadrants in 39 eyes $(38.6 \%)$, and total retinal detachment was observed in 5 eyes $(5 \%)$.

Before the operation, PVR grade $A$ was determined in 96 eyes, PVR grade $B$ in 4 eyes, and PVR grade $C$ in I eye. SB with an encircling band was used in 49 eyes (48.5\%), SB alone in 34 eyes (33.7\%), and an encircling buckle alone in 18 eyes (I7.8\%). Subretinal fluid drainage was performed 69 eyes (68.3\%). Intravitreal air or gas was injected in 25 eyes (24.8\%).

Reattachment was achieved with a single surgery in 67 eyes (66.7\%). In the remaining 34 eyes (33.3\%), additional surgery was required. When the factors that might affect anatomical success (duration of disease, lens status, extent of detachment, surgical method, preoperative risk factors and PVR stage) were examined, PVR stage was found to be the only factor that negatively affected anatomical success $(p=0.027$; $r=0.22$ ). As a reoperation method, $P P V+$ silicone oil/gas tamponade was applied in 28 patients $(27.7 \%)$ due to PVR development. In 6 patients (6\%) it was possible to obtain a reattached retina with band reposition.

At the end of the follow-up period, BCVA increased $\geq I$ line in 70 eyes (69.3\%), remained unchanged in 22 eyes ( $21.8 \%)$, and decreased in 9 eyes (8.9\%). Mean BCVA was $0.23 \pm 0.28$ decimals and $0.4 I \pm 0.3 I$ decimals before and after surgery, respectively $(p<0.001)$.

Subretinal hemorrhage developed in 2 patients as an intraoperative complication. A gas tamponade in the supine position was administered to patients with subretinal hemorrhage at the end of the surgery. Muscle trauma (inferior rectus rupture) developed in 2 patients and a primary repair was performed during surgery. The mean preoperative IOP was $13.1 \pm 1.8 \mathrm{~mm} \mathrm{Hg}$ and the mean postoperative value was 13.9 $\pm 3.1 \mathrm{~mm} \mathrm{Hg}$. The IOP of 4 patients increased $5 \mathrm{mmHg}$ according to the preoperative IOP, or above $21 \mathrm{mmHg}$. Medical treatment was applied to control the IOP of these patients.

\section{Discussion}

Despite new developments and methods in vitreoretinal surgery, classic detachment surgery based on SB retains its place in the treatment of RRD. The purpose of buckling surgery is to provide anatomical reattachment in the retina and thus obtain visual rehabilitation.

In the literature, Inal et al. (4) reported myopia as the most common cause of RRD, while an idiopathic category was identified by Bardak et al. (5), and pseudophakia was cited at $20 \%$ by Akmaz et al. (6) In our study, idiopathic causes and myopia were the most common, with $35 \%$ each. In similar studies, risk factors and causes have been determined in different proportions (I). Pseudophakia was the cause in very few patients in our study compared to other publications. We think that this is due to the fact that the mean age of our patients was very low (33 years).

Reisoğlu et al. (7) reported that $53.5 \%$ of all cases presented at the clinic within I month of the onset of retinal detachment and $15 \%$ presented after 3 months. The success rate of SB surgery performed in these patients was $98.7 \%$ and $86.8 \%$, respectively. In our study, $82 \%$ of the patients presented within I month. We observed no correlation between the length of time before presentation and functional or anatomical success.

In SB surgery, the rate of retinal reattachment is between $78 \%$ and $96 \% .13 .14$ In a study performed by Quijano et al. (8), it was reported that the rate of primary and final anatomical success was $96.7 \%$ and $100 \%$, respectively. The mean preoperative BCVA was $0.3 \pm 0.3 \mathrm{I} \log M A R$ and the mean postoperative BCVA was $0.1 \pm 0.2 \log M A R(p<0.00 I)$ Gogie et al. (9) reported that anatomical success (reattachment of retina) was achieved in 22 (95.63\%) of 23 eyes with SB surgery. All retinas remained attached 2 years later. Significant improvement in mean VA was achieved at the end of follow-up $(1.09 \pm 0.46 \log M A R)$ compared with the preoperative VA $(1.77 \pm 0.28 \log M A R)(p<0.00 I)$.

In our study, the retina was reattached with SB in $66.7 \%$ of the eyes. In terms of functional success, studies in the literature have described rates between $47 \%$ and $88 \%(5,6,7$, 10) Our rate of functional success was $69.3 \%$. It is acknowledged, however, that anatomical success and functional success don't always correlate (II). It is accepted that the most important factor affecting functional success is high preoperative VA $(1 \mathrm{I}, 12)$. It has been reported that the visual prognosis is poorer in retinal detachment with macula involvement (I3). A review of similar studies indicated that anatomical and functional success rates were low in eyes with aphakia or macular involvement. The notable reason for reattachment failure in our study was preoperative PVR. Macular involvement did not affect anatomical success; however, there was a negative correlation with functional success.

Although SB is an effective surgical technique in noncomplicated cases of RRD, it is not a totally uncomplicated technique. The most common complication observed in our 
study was a temporary increase in IOP, seen in $4(4 \%)$ patients. This rate has been reported as between 3.3\% and $16 \%$ in various publications $(4,14,15)$. Another complication seen in our research was the development of subretinal hemorrhage in 2 patients. PVR was the most serious complication reported in PPV surgery in $8 \%$ to $20 \%$, and in $5 \%$ to $10 \%$ of SB surgery (I7). In our study, the development of PVR after surgery was detected in 16 eyes (I5.8\%).

In conclusion, when SB surgery is performed in the treatment of RRD with the appropriate indications, it is an easy method to apply, has a high success rate, a low complication rate, and allows for secondary surgery when it fails.

\section{Disclosures}

Peer-review: Externally peer-reviewed.

Conflict of Interest: None declared.

Authorship Contributions: Involved in design and conduct of the study (AAK, GD, SA); preparation and review of the study (AAK, ZTA); data collection (ZTA, GD); and statistical analysis (AAK, OB).

\section{References}

I. Schepens CL, Marden D. Data on the natural history of retinal detachment. I. Age and sex relationships. Arch Ophthalmol 1961;66:63I-42. [CrossRef]

2. Kishore K, Peyman GA. Vitreoretinal surgical techniques. In: Peyman GA, Meffert S, Conway MD, Chou F, editors. Techniques of Scleral Buckling for Retinal Detachment Repair. London: Martin Dunitz; 200I:7I-96.

3. The classification of retinal detachment with proliferative vitreoretinopathy. Ophthalmology 1983;90:121-5. [CrossRef]

4. İnal A, İnal B, Bayraktar Z, et al. Yırtıklı retina dekolmanında skleral çökertme cerrahisi sonuçlarımız. Ret-Vit 2004;12:16-2I.

5. Bardak Y, Çekiç O, Tığ Ş, Kendir F. Scleral Buckling Results in Rhegmatogenous Retinal Detachment. Ret-Vit 2006; I4:20I-4.

6. Akmaz O, Alauf A, Uzunel U, Yüksel B, Küsbeci T. Yırtıklı retina dekolmanında skleral çökertme cerrahisi sonuçlarımız. Ret-Vit 2015;23:224-30.
7. Hasanreisoğlu B, Aksünger A, Or M, Önol M, Öz Ö, Akbatur $\mathrm{HH}$, et al. Conventional Surgery Results of 1015 Primary Rhegmatogenous Retinal Detachments. Ret-Vit 1996;।:482-91.

8. Quijano C, Alkabes M, Gómez-Resa M, Oleñik A, Villani E, Corcóstegui B. Scleral buckling in phakic uncomplicated primary rhegmatogenous retinal detachment: long-term outcomes. Eur J Ophthalmol 2017;27:220-5. [CrossRef]

9. Gogia V, Venkatesh P, Gupta S, Kakkar A, Garg S. Endoilluminator-assisted scleral buckling: our results. Indian J Ophthalmol 20| 4;62:893-4. [CrossRef]

10. Laatikainen L, Harju H, Tolppanen EM. Post-operative outcome in rhegmatogenous retinal detachment. Acta Ophthalmol (Copenh) 1985;63:647-55. [CrossRef]

II. Singh M. Surgery of aphakic retinal detachment. Br J Ophthalmol 1988;72:820-2. [CrossRef]

12. Wilkinson CP. What is the "best" way to fix a routine retinal detachment? In: Lewis H, Ryan SJ, editors. Medical and surgical retina. St Louis: Mosby; 1994. p. 85-102.

13. La Heij EC, Derhaag PF, Hendrikse F. Results of scleral buckling operations in primary rhegmatogenous retinal detachment. Doc Ophthalmol 2000;100:17-25. [CrossRef]

14. Afrashi F, Erakgun T, Akkin C, Kaskaloglu M, Mentes J. Conventional buckling surgery or primary vitrectomy with silicone oil tamponade in rhegmatogenous retinal detachment with multiple breaks. Graefes Arch Clin Exp Ophthalmol 2004;242:295300. [CrossRef]

15. Miki D, Hida T, Hotta K, Shinoda K, Hirakata A. Comparison of scleral buckling and vitrectomy for retinal detachment resulting from flap tears in superior quadrants. Jpn J Ophthalmol 200।;45: |87-9|. [CrossRef]

16. Han DP, Mohsin NC, Guse CE, Hartz A, Tarkanian CN. Comparison of pneumatic retinopexy and scleral buckling in the management of primary rhegmatogenous retinal detachment. Southern Wisconsin Pneumatic Retinopexy Study Group. Am J Ophthalmol 1998; | 26:658-68. [CrossRef]

17. Girard P, Mimoun G, Karpouzas I, Montefiore G. Clinical risk factors for proliferative vitreoretinopathy after retinal detachment surgery. Retina 1994;14:417-24. [CrossRef] 